\title{
Foot posture, foot function and low back pain: the Framingham Foot Study
}

\author{
Hylton B Menz ${ }^{1,2,3^{*}}$, Alyssa B Dufour ${ }^{2,4}$, Jody L Riskowski ${ }^{2,3}$, Howard J Hillstrom ${ }^{5}$, Marian T Hannan 2,3 \\ From Australasian Podiatry Council Conference 2013 \\ Sydney, Australia. 2-5 June 2013
}

\section{Background}

Low back pain is a highly prevalent problem world-wide. Abnormal foot posture and function have been proposed as possible risk factors for low back pain, but this has not been explored in detail.

\section{Methods}

Data were collected on 1,930 members of the Framingham Study who completed the foot examination in 2002-2005. Low back pain, aching or stiffness on most days was documented on a body chart. Foot posture and foot function were evaluated using the Tekscan MatS$\mathrm{can}^{\circledR}$ system. Foot posture was categorized as normal, planus or cavus using static weightbearing measurements of the arch index. Foot function was categorized as normal, pronated or supinated using the center of pressure excursion index derived from dynamic foot pressure measurements. Asymmetry in foot posture and foot function was also determined. Sex-specific multivariate logistic regression models were used to examine the associations of foot posture, foot function and asymmetry with low back pain, adjusting for relevant confounding variables.

\section{Results}

Low back pain was reported by 661 (34\%) participants, including 404 (37\%) women and 257 (30\%) men. Foot posture showed no association with low back pain. However, pronated foot function was significantly associated with low back pain in women (odds ratio $[\mathrm{OR}]=1.51,95 \%$ confidence interval $[\mathrm{CI}] 1.1$ to $2.07, \mathrm{P}=0.011$ ) and this association remained significant after adjusting for age, weight, smoking and depressive symptoms $(\mathrm{OR}=1.48,95 \%$
CI 1.07 to $2.05, \mathrm{P}=0.018$ ). Asymmetry in foot posture or foot function was not significantly associated with low back pain.

\section{Conclusion}

This is the first population-based study to examine the associations of foot posture and function with low back pain using objective biomechanical measurements. The findings suggest that pronated foot function may contribute to the development of low back symptoms in women. Interventions which modify abnormal foot function, such as foot orthoses, may therefore have a role in the prevention and treatment of low back pain.

\section{Author details \\ 'Lower Extremity and Gait Studies Program, La Trobe University, Bundoora, Victoria 3086, Australia. ${ }^{2}$ Institute for Aging Research, Hebrew SeniorLife, Boston, Massachusetts 02131, USA. ${ }^{3}$ Harvard Medical School, Boston, Massachusetts 02131, USA. ${ }^{4}$ Boston University School of Public Health, Boston, Massachusetts 02131, USA. ${ }^{5}$ Hospital for Special Surgery, New York, New York 10021, USA.}

Published: 31 May 2013

doi:10.1186/1757-1146-6-S1-027

Cite this article as: Menz et al:: Foot posture, foot function and low back pain: the Framingham Foot Study. Journal of Foot and Ankle Research 2013 6(Suppl 1):O27.

\footnotetext{
* Correspondence: h.menz@latrobe.edu.au

'Lower Extremity and Gait Studies Program, La Trobe University, Bundoora, Victoria 3086, Australia

Full list of author information is available at the end of the article
}

(c) 2013 Menz et al; licensee BioMed Central Ltd. This is an Open Access article distributed under the terms of the Creative Commons 